\title{
The metabolic response of plants to oxygen deficiency
}

\author{
Carlos Antônio Ferreira de Sousa ${ }^{1, *}$ and Ladaslav Sodek ${ }^{2}$
}

${ }^{1}$ Empresa Brasileira de Pesquisa Agropecuária - Embrapa Meio-Norte, Av. Duque de Caxias, 5650, Bairro Buenos Aires, C P 01,
64006-220, Teresina, PI, Brasil; ${ }^{2}$ Departamento de Fisiologia Vegetal, Instituto de Biologia, CP 6109, Unicamp, 13083-970,
Campinas, SP, Brasil; * Corresponding author: cafsousa@cpamn.embrapa.br
Received: 01/08/2002, Accepted: 02/09/2002

Plants, under natural or experimental conditions, can be subject to a range of $\mathrm{O}_{2}$ concentrations from normal (normoxia) through deficient (hypoxia) to total absence (anoxia). Many metabolic processes are affected by $\mathrm{O}_{2}$ deficiency but the most studied events are those related to respiration and metabolism of $\mathrm{N}$. In the absence of a terminal electron acceptor for the electron transport chain, the tricarboxylic acid cycle functions only partially and in both directions. Acidification of the cytosol occurs and pyruvate, the product of glycolysis, is transformed to lactate and ethanol, which represent the main fermentation reactions in plants. Alanine is the third most important product of anaerobic metabolism, resulting from high rates of amino acid interconversion in which transaminases such as alanine aminotransferase play an important role. The role of alanine accumulation under anaerobiosis is not clear and appears to be independent of the source of $\mathrm{N}$ whether $\mathrm{NO}_{3}^{-}, \mathrm{NH}_{4}^{+}$or $\mathrm{N}_{2}$. How nitrate exerts its beneficial effect on tolerance of root hypoxia in waterlogged plants is still not clearly understood. Such aspects of $\mathrm{N}$ metabolism pose interesting challenges for future research on metabolic responses of plants to oxygen deficiency.

Key words: anoxia, hypoxia, $\mathrm{N}$ metabolism, fermentation products.

Respostas metabólicas de plantas à deficiência de oxigênio: As plantas, em condições naturais ou experimentais, podem ser submetidas à disponibilidade de $\mathrm{O}_{2}$ que varia desde os teores normais (normoxia), passando pela deficiência (hipoxia) ou até mesmo pela ausência (anoxia). Vários processos metabólicos são afetados pela deficiência de $\mathrm{O}_{2}$, porém os eventos mais estudados são aqueles relacionados à respiração e ao metabolismo de $\mathrm{N}$. Na ausência de um aceptor eletrônico terminal na cadeia de transporte de életrons, o ciclo do ácido tricarboxílico passa a funcionar parcialmente e em ambas as direções. Ocorre a acidificação do citosol e o piruvato, produto da glicólise, é transformado em lactato e etanol, que representam as principais reações fermentativas das plantas. A alanina é o terceiro mais importante produto do metabolismo anaeróbico, sendo resultante de altas taxas de interconversão entre os aminoácidos em que as transaminases, tais como alanina aminotransferase, desempenham um papel importante. $\mathrm{O}$ acúmulo de alanina sob anaerobiose parece ser independente da fonte de $\mathrm{N}: \mathrm{NO}_{3}-\mathrm{NH}_{4}^{+}$ou $\mathrm{N}_{2}$ e o seu papel precisa ser esclarecido. Da mesma forma, ainda não está completamente entendido como o $\mathrm{NO}_{3}^{-}$exerce seu efeito benéfico sobre a tolerância radicular à hipoxia em plantas encharcadas. Tais aspectos do metabolismo de $\mathrm{N}$ colocam desafios interessantes para as futuras pesquisas sobre as respostas das plantas à deficiência de oxigênio.

Palavras-chave: hipoxia, anoxia, metabolismo de N, produtos da fermentação.

\footnotetext{
Abbreviations: ADH (alcohol dehydrogenase); AlaAT (alanine aminotransferase); AspAT (aspartate aminotransferase); ANPs (anaerobic proteins); OAA (oxaloacetic acid); OAA-DC (oxaloacetic acid decarboxylase); ETC (electron transport chain); GabaOT (Gaba oxoglutarate transaminase); Gaba-PT (Gaba pyruvate transaminase); GS/GOGAT (glutamine synthetase/glutamine oxoglutarate amidotransferase); GluDC (glutamate decarboxylase); LDH (lactate dehydrogenase); NTP (nucleotide triphosphate); PAGE (polyacrylamide-gel electrophoresis); PDC (pyruvate decarbolylase); NR/NiR (nitrate/nitrite reductase); TCA cycle (tricarboxylic acid cycle); $2 \mathrm{OG}$ (2-oxoglutarate).
} 


\section{INTRODUCTION}

Oxygen is indispensable to higher plants for metabolism and growth. However, under natural or experimental conditions plants can be subjected to a great range of oxygen availability, from normal levels (normoxia) through deficiency (hypoxia) to total absence (anoxia). According to Drew (1997), normoxia prevails when oxygen supply does not limit oxidative phosphorylation. For hypoxia, the partial pressure of oxygen is low enough to limit the production of ATP by mitochondria whereas anoxia is attained when the mitochondrial production of ATP is insignificant compared to that generated by glycolysis and fermentation.

Oxygen deficiency of root systems occurs frequently in nature (Kennedy et al., 1992) affecting the majority of plants at some time during their life cycle (Jackson et al., 1982). In the field, roots can be subject to oxygen deficiency soon after strong rainfall, since the soil usually becomes flooded for a short or longer period depending on its drainage capacity (Huang et al., 1994a). In other situations, oxygen deficiency can occur due to the anatomical structure of some tissues that impede gas exchange (Thompson and Greenway, 1991; Perata and Alpi, 1993). Nevertheless the majority of plant tissues can tolerate oxygen deficiency for short periods before suffering irreversible damage (Kennedy et al., 1992).

Plants whose root system is flooded can undergo morphological and anatomical changes that enhance gas exchange in an attempt to avoid or minimize oxygen deficiency (Perata and Alpi, 1993). In order to tolerate hypoxic stress, they may further undergo biochemical and metabolic changes. This review will focus on the more important biochemical and metabolic changes relating to the products of fermentation and the $\mathrm{N}$ pool together with special emphasis on alanine accumulation and the importance of nitrate in counteracting the adverse effects of oxygen deficiency.

\section{Metabolic events affected by oxygen deficiency}

Oxygen deficiency in plants, brought about by waterlogging of the root system is a very common event in nature. Its consequences vary from the increase in biomass of the shoot in relation to the root (BarrettLennard et al., 1988; Huang and Johnson, 1995) to the loss of plants, due to seasonal flooding (Kennedy et al.,
1992). The relative reduction in root biomass and the shift in allocation of metabolites to the shoot during flooding are probably the result of a metabolic adaptation aimed at diminishing the demand for oxygen by the root system (Naidoo and Naidoo, 1992; Huang et al., 1994b).

Reduction in photosynthetic activity is another consequence of waterlogging and can be attributed to several factors: lower water potential and stomatal conductance; lower activities of photosynthetic enzymes; impaired transport of photoassimilates due to lower sink activity; and lower chlorophyll content (Huang et al., 1994b; Liao and Lin, 1994).

Under oxygen deficiency, glycolysis and fermentation can exceed the aerobic metabolic rate and become the only pathway for energy production. Here, mitochondrial respiration stops in the absence of a terminal electron acceptor. As a result, the generation of ATP falls from 36 to 2 moles per mole of glucose metabolised (Fox et al., 1994; Morard and Silvestre, 1996). Although the coupling of glycolysis with fermentation allows only limited synthesis of ATP, by substrate level phosphorylation, it regenerates $\mathrm{NAD}^{+}$and removes excess protons (Fan et al., 1997). In such situations, the "Pasteur effect" can occur, that is, glycolysis accelerates under anoxia in order to meet the demands for ATP, in spite of its lower efficiency in ATP production compared to aerobic respiration (Vanlerberghe et al., 1990; Vanlerberghe and Turpin, 1990). However, the "Pasteur effect" per se does not show any correlation with tolerance to flooding (Kennedy et al., 1992).

The supply of carbohydrates and the regulation of carbohydrate and energy metabolism are important for enduring hypoxic stress (Andreev et al., 1991; Schlüter et al., 1996). Phloem transport is inhibited by hypoxia such that the supply of carbohydrates to the roots diminishes (Barta, 1987; Waters et al., 1991a). In spite of this, the roots of many plants accumulate sugars (Limpinuntana and Greenway, 1979; Barta, 1987; BarrettLennard et al., 1988; Fan et al., 1988; Schlüter et al., 1996; Albrecht and Biemelt, 1998), amino acids (Barta, 1988; Fan et al., 1988; Reggiani et al., 1988; 2000) and reserves, such as starch (Barta, 1987) and fructans (Albrecht et al., 1993; Schlüter et al., 1996; Albrecht et al., 1997; Albrecht and Biemelt, 1998), when subjected to oxygen deficiency. While some authors explain the accumulation of these metabolites through a reduction 
in growth rate (Limpinuntana and Greenway, 1979; Barrett-Lennard et al., 1988), others suggest it is due to a reduction in respiratory rate (Huang and Johnson, 1995) that is greater than the reduction in supply via phloem (Atwell et al., 1985; Barta, 1987).

According to Bouny and Saglio (1996), the limiting step of glycolysis under anaerobiosis is the phosphorylation of hexoses by kinases, due to the fall in $\mathrm{pH}$ and ATP concentration. It is also probable that fermentation is combined with some partial activity of the TCA cycle, as proposed by Fox et al. (1994), to explain the greater efficiency of some species under anoxia compared to others. Several authors have used this line of thinking to discuss their results (Menegus et al., 1988; 1989; 1991; Vanlerberghe et al., 1990).

Although mitochondrial ultrastructure can be affected by anaerobiosis (Andreev et al., 1991), all enzymes of the TCA cycle continue present (Kennedy et al., 1992). In spite of being of little quantitative importance, the partial operation of the TCA cycle may play an important qualitative role in providing precursors for several biosynthetic pathways such as assimilation of $\mathrm{NH}_{4}^{+}$or synthesis of the heme molecule (Ricard et al., 1994). The advantages of these alternative strategies to anaerobic fermentation are based on the increase in ATP production per mole of substrate fermented, the formation of $\mathrm{NAD}^{+}$, the supply of a sink for reducing agents and the maintenance of cellular $\mathrm{pH}$.

\section{Metabolic products in plants under $\mathrm{O}_{2}$ deficiency}

When aerobic organisms are deprived of $\mathrm{O}_{2}$, mitochondrial oxidative phosphorylation is inhibited, while glycolysis and fermentation pathways are promoted, leading to the accumulation of diverse products such as ethanol, lactate, Ala, Gaba, succinate and malate (Fan et al., 1988; 1997).

The major products of fermentation in plant tissues are ethanol, lactate and Ala, all three derived from pyruvate (figure 1), the final product of glycolysis (Ricard et al., 1994; Drew, 1997). Although these 3 pathways compete for pyruvate, pyruvate itself accumulates under anoxia (Streeter and Thompson, 1972a; Reggiani et al., 1988; Vanlerberghe and Turpin, 1990; Good and Muench, 1993). The accumulation of pyruvate results from a decline in rate of oxidation and increase in rate of synthesis, through decarboxylation of OAA, due to increased activity of OAA-DC under hypoxia, as the $\mathrm{pH}$ falls (Streeter and Thompson, 1972a). Part of this increase in pyruvate has also been attributed to the induction of the malic enzyme, in hypoxic roots of maize (Roberts et al., 1992). Edwards et al. (1998) found that the malic enzyme is activated by a drop in $\mathrm{pH}$ of the cytoplasm brought about by severe hypoxic conditions obtained "in vivo", where respiration becomes negligible. Therefore, only such extreme conditions of high respiratory demand and cytoplasmic acidity would allow the malic enzyme to play some role in respiration under hypoxia.

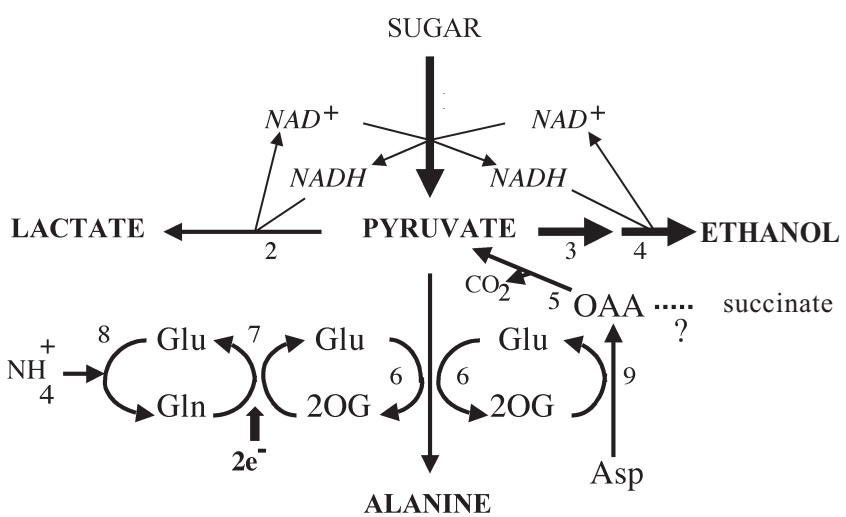

Figure 1. Pyruvate metabolism in plants under oxygen deficiency. 1 = glycolysis; 2 = LDH (lactate dehydrogenase); $3=$ PDC (pyruvate decarbolylase); $4=\mathrm{ADH}$ (alcohol dehydrogenase); 5 = OAA-DC (oxaloacetic acid decarboxylase) or MDH (malate dehydrogenase) + malic enzyme; 6 $=$ AlaAT; 7 = GOGAT (glutamine oxoglutarate amidotransferase); $8=\mathrm{GS}$ (glutamine synthetase); $9=$ AspAT (aspartate aminotransferase).

Ethanol, lactate and Ala can be produced simultaneously in plants under $\mathrm{O}_{2}$ deficiency, although in different relative quantities, depending on the species and the degree of $\mathrm{O}_{2}$ deficiency (Ricard et al., 1994). Ethanol is probably the major fermentation product of higher plant tissues whether tolerant or not to $\mathrm{O}_{2}$ deficiency (Smith and ap Rees, 1979) and is produced by the sequential action of PDC and ADH, enzymes induced in tissues under $\mathrm{O}_{2}$ deficiency (Good and Crosby, 1989a; Roberts et al., 1989; Russell et al., 1990; Xia and Saglio, 1992; Bouny and Saglio, 1996; Germain et al., 1997; Porterfield et al., 1997). The importance of ethanol fermentation lies in its greater efficiency, on a molar basis, in relation to lactate fermentation, for the generation of $\mathrm{NAD}^{+}$and the consumption of protons (Fan et al., 1997; Kato-Noguchi, 2000). Furthermore, the concentrations of ethanol normally found in plants are insufficient to cause 
toxicity (Jackson et al., 1982). On the other hand, ethanol is not easily metabolized and, in view of its solubility in lipid bi-layer of cellular membranes (Drew, 1997), it can almost entirely diffuse out into the surrounding medium, resulting in the loss of carbon (Bertani et al., 1980; Good and Crosby, 1989a; Perata and Alpi, 1993).

The enzyme LDH is induced under hypoxia and its product, lactate, frequently produced before ethanol soon after transfer of the plant to anoxia, when acidification of the cytosol signals the production of ethanol, as shown by Davies et al. (1974) and confirmed by other authors (Roberts et al., 1992). This sequence of events is known as the Davies-Roberts hypothesis (Kennedy et al., 1992; Rivoal and Hanson, 1994; Kato-Noguchi, 2000). On the other hand, Kato-Noguchi (2000) showed that, in lettuce roots, ethanolic fermentation could be induced even in the presence of $\mathrm{O}_{2}$, without previous formation of lactate, just by inhibiting oxidative electron transport. The author interpreted the results as being an indication that ethanolic fermentation may not be regulated directly by $\mathrm{O}_{2}$ concentration.

Lactate fermentation is frequently associated with acidification of the cytosol (Davies et al., 1974; Roberts et al., 1992; Ricard et al., 1994), although much of the lactate formed is stored in the vacuole or released to the surrounding medium (Xia and Saglio, 1992; Rivoal and Hanson, 1994). Nevertheless, a correlation is not always found between lactate accumulation and a fall in $\mathrm{pH}$ (Menegus et al., 1989; Saint-Ges et al., 1991). LDH itself stops producing lactate when the $\mathrm{pH}$ drops below 6.9 , in view of its alkaline pH optimum (Davies et al., 1974). Ethanolic fermentation, on the other hand, causes acidification of the cytoplasm, only if the $\mathrm{CO}_{2}$ liberated by decarboxylation of pyruvate does not escape to the surrounding medium (Roberts et al., 1992).

Presently, there is evidence that other sources of acidification of the cytoplasm exist just as, or more effective than lactate, such as the accumulation of protons associated with NADH and NADPH (VanToai and Bolles, 1991) or the hydrolysis of ATP (Menegus et al., 1991; Xia and Saglio, 1992; Kato-Noguchi, 2000; Gout et al., 2001). Saint-Ges et al. (1991), despite having obtained a correlation between the fall in $\mathrm{pH}$ and the levels of NTP in anoxic root tip cells of maize, discard the liberation of inorganic phosphorous observed in the cytoplasmic compartment as the main cause of the drop in $\mathrm{pH}$. These authors suggest that the fall in ATP concentration observed during the transition from normoxia to hypoxia could have had a strong influence on the activities of electrogenic ATPases, responsible for the pumping of protons $\left(\mathrm{H}^{+}\right.$-ATPases $)$across the plasmalema and tonoplast, since the affinity of both for ATP is low. Thus the active electrogenic extrusion of protons may have been affected, leading to a decline in cytoplasmic $\mathrm{pH}$.

The data of Gout et al. (2001) also suggest that plasmalema proton pumping ATPase activity is blocked during anoxia, but not because of a decrease in the NTP pool. Initial cytoplasmic acidification occurred prior to lactate formation and appeared to be closely related to NTP concentration, leading to the conclusion that the release of protons accompanying phosphate-liberating NTP hydrolysis was the principal cause of the initial drop in cytoplasmic $\mathrm{pH}$ during anaerobic stress. Blockage of the proton pumping ATPase activity during anoxia, possibly due to the release of $\mathrm{Ca}^{2+}$ from cellular compartments, was seen as beneficial since it limits ATP consumption.

Succinate is another metabolite that stands out during hypoxia in several reports. It was observed to accumulate in the shoot of seedlings (Menegus et al., 1988; 1989; 1991) and in cells of algae (Vanlerberghe et al., 1989; 1990; Vanlerberghe and Turpin, 1990) subjected to $\mathrm{O}_{2}$ deficiency. Its production resulted from the partial operation of the TCA cycle, in the reverse direction. The authors pointed out the importance of this diversion since it may be coupled to carbon flow in the normal direction to supply oxoglutarate for nitrogen metabolism under $\mathrm{O}_{2}$ deficiency. They also suggest that the production of succinate could confer tolerance to anoxia, through the production of ATP, albeit limited, inside the mitochondria and serve as a means of regulating the cellular redox potential. Furthermore, Menegus et al. (1989) suggested that the succinate/lactate ratio could be taken as a means of classifying plants as to their tolerance to anoxia. However, Roberts et al. (1992) concluded that the accumulation of succinate in maize root tips during hypoxia is simply a consequence of aspartate and malate metabolism, and not due to any fermentation reaction, which would discard any relation of succinate with the regulation of cytoplasmic $\mathrm{pH}$ or the production of energy.

Malate has also been related to $\mathrm{O}_{2}$ deficiency in several species, although both its accumulation and role 
in plant tissues under $\mathrm{O}_{2}$ deficiency is controversial. Joly (1994), in a study of tropical arboreal species adapted to waterlogged soil, observed that during the initial stages of hypoxic stress the roots do not produce large quantities of ethanol and lactate, transforming some of the pyruvate to the production of malate. Here, the quantity of malate produced was dependent on the quantity of oxygen that diffused from aerial parts to the roots. On the other hand, while Smith and ap Rees (1979), Fan et al. (1988) and Vanlerberghe et al. (1990) did not observe accumulation of malate in roots of plants or anoxic cells of algae, respectively, and Vanlerberghe et al. (1990) characterized malate as a intermediate of succinate synthesis, Roberts et al. (1992) conferred an important role for malate in hypoxic metabolism of maize root tips, where it would be transformed into pyruvate by the malic enzyme. Pyruvate, in turn would undergo transamination to form Ala.

\section{Metabolism of amino acids in plants deficient in $\mathrm{O}_{2}$}

The majority of studies carried out with plants where the roots or shoots are subjected to a deficiency in $\mathrm{O}_{2}$ revealed increases in levels and interconversion of free amino acids (Streeter and Thompson, 1972a,b; Roberts et al., 1992; Good and Muench, 1993; Fan et al., 1997; Reggiani, 1999; Reggiani et al., 2000), even though total $\mathrm{N}$ remained constant (Barta, 1988) or even diminished (Bacanamwo and Purcell, 1999a,b). Among the amino acids that accumulate under anaerobiosis, Ala stands out: for example it attained $1.2 \%$ of the root dry weight and $31-32 \%$ of the free amino acid fraction in rice, representing the third main product of fermentation (Reggiani et al., 1985). According to Reggiani et al. (1988), the increase in Ala content is due to interconversion of free amino acids, whereas the increase in free amino acids is due to proteolysis. They concluded that the origin of Ala that accumulated in detached roots of rice under anoxia, $77.5 \%$ was due to amino acid interconversion and $22,5 \%$ to proteolysis.

Under anaerobiosis, the GS/GOGAT system appears to play an important role in the accumulation of free amino acids, especially Ala and Gaba, through its participation in the synthesis of Glu (Reggiani et al., 1993a; 2000). It is believed that transamination, indirectly with aspartate, via AspAT (Streeter and Thompson, 1972a,b; Vanlerberghe and Turpin, 1990; Vanlerberghe et al., 1991) and directly with Glu (Smith and ap Rees, 1979; Reggiani et al., 1988) through AlaAT (Good and
Crosby, 1989b), is the mechanism responsible for supplying the $\mathrm{N}$ of Ala. Other possible sources of Ala are the $\beta$-decarboxylation of aspartate, the reductive amination of pyruvate (Vanlerberghe et al., 1991) and proteolysis (Reggiani et al., 1988). $\beta$-decarboxylation of aspartate and the reductive amination of pyruvate were discarded, however, in studies with anaerobic leaves of radish (Streeter and Thompson, 1972a) and with hypoxic roots of rice (Reggiani et al., 1988) and barley (Good and Muench, 1993).

Vanlerberghe et al. (1991) suggested that the accumulation of Ala is directly dependent on anaerobic assimilation of $\mathrm{NH}_{4}^{+}$and relate fermentation metabolism to the N "status" of the plant. Thus, the synthesis of Ala would allow detoxification of $\mathrm{NH}_{4}^{+}$, without affecting the energy state or redox potential of the cell and, at the same time, form a pool of $\mathrm{N}$ that could be used in the synthesis of amino acids, on return to normoxia. When present, $\mathrm{NO}_{3}{ }^{-}$also appears to be an important source of $\mathrm{N}$ for Ala accumulation (Sousa and Sodek, 2002). Mineral N is not, however, essential for this process, since soybean plants totally dependent on $\mathrm{N}_{2}$ fixation (no mineral $\mathrm{N}$ present) also accumulate Ala (Puiatti and Sodek, 1999). In the green alga Senastrum minutum, Ala also accumulated in the absence of mineral $\mathrm{N}$ but was limited, arising principally from aspartate metabolism (Vanlerberghe et al, 1991) as suggested for soybean (Puiatti and Sodek, 2001; Sousa and Sodek, 2002). Nevertheless, the significance of alanine formation under hypoxia is poorly understood, since its formation from pyruvate does not regenerate $\mathrm{NAD}^{+}$. Ala accumulation, on the other hand, does not cause toxicity to the cell, an important property for anoxia tolerance (Drew, 1997).

Another amino acid that accumulates under several stress conditions is Gaba (Ricard et al., 1994; Serraj et al., 1998), including $\mathrm{O}_{2}$ deficiency (Streeter and Thompson, 1972a,b; Reggiani et al., 1988; Menegus et al., 1989; Crawford et al., 1994; Reggiani et al., 2000; Sousa, 2001). Its synthesis occurs principally by the $\alpha$ decarboxylation of Glu, a reaction catalysed by GluDC (Fan et al., 1988; Crawford et al., 1994). In view of the sharp acid pH optimum of GluDC (Snedden et al., 1992), increased synthesis of Gaba can be explained by the effect of reduced cytoplasmic $\mathrm{pH}$ that follows $\mathrm{O}_{2}$-deficiency. However, Roberts et al. (1992) reason that while a decline in cellular $\mathrm{pH}$ may well be necessary for the synthesis of Gaba, it does not appear to be the only factor, since the 
accumulation of Gaba in hypoxic roots of maize occurred long after the decline in $\mathrm{pH}$.

More recent work (see reviews by Shelp et al., 1999 and Kinnersley and Turano, 2000) has shown that anoxia and several other stress conditions lead to cytosolic increases in $\mathrm{Ca}^{2+}$ which, through $\mathrm{Ca}^{2+} /$ calmodulin, stimulate GluDC activity. Activation of GluDC by this mechanism under anoxia has been shown by Aurisano et al. (1995). The $\mathrm{Ca}^{2+} /$ calmodulin mechanism may operate at initial stages of stress, before the $\mathrm{pH}$ has dropped, while the $\mathrm{pH}$ effect on GluDC is seen as a subsequent event which depends on the duration or severity of the stress bringing about a fall in $\mathrm{pH}$ (Kinnersley and Turano, 2000). However, decarboxylation of Glu is not the only reaction leading to the synthesis of Gaba. It may also be formed, in smaller amounts, by the oxidative breakdown of polyamines (Serraj et al., 1998) and, possibly, by transamination of Ala or Glu (Wallace et al., 1984) via the enzymes Gaba-PT and Gaba-OT, respectively.

Gaba accumulation under $\mathrm{O}_{2}$ deficiency results from both an increased rate of synthesis and a low rate of catabolism. The latter arises because amination of pyruvate by Gaba stops under hypoxia, in view of its $\mathrm{pH}$ optimum of 8,9 (Streeter and Thompson, 1972a,b), well above the values normally attained under these conditions. According to Streeter and Thompson (1972a), $\mathrm{pH}$ has an important influence on Gaba levels, regulating the rate of synthesis and utilization, whereas Menegus et al. (1989) and Crawford et al. (1994) suggested the involvement of Gaba formation in regulation of cytosolic pH. According to Crawford et al. (1994), the different conclusions obtained with respect to the role of Gaba on $\mathrm{pH}$ control may be due to the use of permeant weak acids instead of hypoxia to induce acidification of the cell sap, or to differences between mature vacuolated mesophyll cells and immature nonvacuolated cells of root tips.

Several reports show a significant accumulation of the polyamine putrescine in hypoxic roots of alfalfa (Barta, 1988) and rice (Menegus et al., 1989; Reggiani, 1999). Menegus et al. (1989) and Reggiani (1999) produced evidence that decarboxylation of arginine, forming putrescine, could contribute substantially to the alkalinization of seedling tissues of rice under $\mathrm{O}_{2}$ deficiency.

In spite of these controversies, the majority of authors agree that interconversion of amino acids aids cellular $\mathrm{pH}$ regulation in plant organs under $\mathrm{O}_{2}$ deficiency
(Streeter and Thompson, 1972a,b; Fan et al., 1988; Reggiani et al., 1988; Crawford et al., 1994; Fan et al., 1997; Reggiani, 1999), a characteristic considered to be fundamental for the survival of species under anoxia (Ricard et al., 1994).

\section{Effects of $\mathrm{NO}_{3}{ }^{-}$in plants under $\mathrm{O}_{2}$ deficiency}

$\mathrm{NO}_{3}^{-}$has a profound effect on anaerobic metabolism (Fan et al., 1988; 1997). Its presence in the surrounding medium increases tolerance to flooding (Malavolta, 1954; Trought and Drew, 1981; Prioul and Guyot, 1985), apparently through a more efficient regeneration of $\mathrm{NAD}^{+}$ and consumption of protons (Garcia-Novo and Crawford, 1973; Roberts et al., 1985). The subject is however controversial.

Theoretically, the reductive assimilation of $\mathrm{NO}_{3}{ }^{-}$to $\mathrm{NH}_{4}^{+}$may have two functions in plants under $\mathrm{O}_{2}$ deficiency, both contributing to alleviate cytoplasmic acidity: 1) the process consumes 4 moles of $\mathrm{NAD}(\mathrm{P}) \mathrm{H}$ ( 8 electrons) and 8 protons per reaction cycle (Salsac et al., 1987), being more efficient in $\mathrm{NAD}^{+}$generation and consumption of protons than any of the fermentation reactions (Reggiani et al., 1985; Fan et al., 1988; 1997); 2) the process generates hydroxyl ions (Smirnoff and Stewart, 1985), that can counteract the protons generated by hypoxia.

Therefore, nitrate reduction should provide an alternative sink for electrons and in doing so reduce the formation of fermentation products such as ethanol. Consistent with this hypothesis, Garcia Novo and Crawford (1973) found increased NR activities (in vivo assays) in roots of many species under flooding. NR activity also increased under anoxia in coleoptiles of germinating rice, as a result of increased gene expression (Mattana et al., 1996) while activation of NR clearly occurs through the dephosphorylation mechanism in anoxic roots of pea (Glaab and Kaiser, 1993), barley (Botrel et al., 1996) and cucumber (De la Haba et al., 2001), as a result of cellular acidification (Botrel et al., 1996). On the other hand, NR did not increase in seedlings of Echinochloa phyllopogon under such conditions (Fox et al., 1994), though this does not preclude enzyme activation since appropriate assay conditions are needed to detect it. When direct assessments of nitrate reduction and assimilation are made in tissues under $\mathrm{O}_{2}$ deficiency, nitrate reduction and assimilation are reduced (Lee, 
1978). Diminished absorption of nitrate by the roots also contributes strongly to this phenomenon (Lee, 1978). Accumulation of nitrite and its release into the surrounding medium under anoxia suggest that nitrite reduction is the more strongly inhibited reaction (Lee, 1979). Species capable of germinating under anaerobic conditions, such as rice, appear to be a case apart (Reggiani et al., 1993b), since nitrate assimilation is enhanced under anoxia (Reggiani et al., 1993a, b; Kemp and Small, 1993).

Data bearing on the physiological significance of nitrate reduction under $\mathrm{O}_{2}$ deficiency have brought little support for the alternative electron sink hypothesis, again except for rice. In rice it was found that nitrate reduced the production of ethanol (Fan et al., 1997), as would be expected for the hypothesis. However, in excised roots of barley (Lee, 1978) and maize (Reggiani et al., 1985) more, not less, ethanol was produced under anoxia in the presence of nitrate. Care is needed however, in the interpretation of data obtained under anoxia as opposed to the lower degree of $\mathrm{O}_{2}$ deficiency experienced by flooded plants, since Lee (1978) has shown that hypoxia, in contrast to anoxia, had little effect on nitrate assimilation in barley roots. It is still not possible, therefore, to reach a clear explanation for the beneficial effect of nitrate during flooding.

A new and promising line of investigation concerns a minor side reaction of NR that leads to NO production from nitrite (Kaiser et al., 2002; Magalhães et al., 2002). Curiously, the activation of NR under anoxia is accompanied by diminished rates of nitrate reduction which questions the physiological significance of the activation mechanism under such conditions (Kaiser and Huber, 2001). However, since nitrite reduction is more severely affected under anoxia than nitrate reduction, nitrite accumulates favouring NO production (Rockel et al., 2002). Besides its possible role in various physiological processes such as plant-pathogen interactions, NO may act as a signal molecule in stress situations such as anoxia (Magalhães et al., 2002) but the extent to which NR contributes NO for stress signalling must await further investigation (Kaiser and Huber, 2001).

\section{Enzyme activities in plants under $\mathrm{O}_{2}$ deficiency}

Plants respond to anaerobic conditions through changes in the expression of several genes (Russell et al., 1990; Ricard et al., 1994). Polyribosome dissociation occurs under anoxia together with a rapid decline in the synthesis of proteins (Kennedy et al., 1992). The polypeptide profile is altered ( $\mathrm{Lin}$ and Key, 1967; Kennedy et al., 1992), with a reduction in the total number of polypeptides synthesized and an increase in the socalled anaerobic proteins (ANPs) (Sachs et al., 1980; Good and Crosby, 1989a; Bailey-Serres and Freeling, 1990; Drew, 1990; Perata and Alpi, 1993). Anoxia leads to the accumulation of a new set of transcripts and although most pre-stress transcripts are still present only those accumulated during anoxia are translated, producing the ANPs (Russell et al., 1990). This may occur because of the changes in cytoplasmic $\mathrm{pH}$, associated with hypoxia, since at $\mathrm{pH} 6.5$ a set of mRNAs was preferentially translated in hypoxic roots of maize, quite different from the proteins normally synthesized at $\mathrm{pH}$ 7,5 (Kennedy et al., 1992). More recently it has been shown that proteins synthesized during the acclimation period (hypoxia) leading to anoxia are crucial for anoxia tolerance in contrast to those synthesized during anoxia (Chang et al., 2000).

Of the 20 or so known ANPs (Sachs et al., 1996), the most studied include PDC, ADH and LDH (Good and Crosby, 1989a; Russell et al., 1990; Waters et al., 1991b; Christopher and Good, 1996; Germain et al., 1997; Porterfield et al., 1997, Kato-Noguchi, 2000). Several glycolytic enzymes are induced under anaerobiosis (Guglielminetti et al., 1995; Germain et al., 1997), as well as transaminases (Good and Crosby, 1989b; Good and Muench, 1992; Muench et al., 1998). Together with PDC, induction of $\mathrm{ADH}$ was associated with the survival capacity of plants under anoxia (Waters et al., 1991b; Johnson et al., 1994). However, the use of genetically transformed plants to overproduce ADH alone, or PDC and $\mathrm{ADH}$ together, did not improve the survival of germinating rice under anoxia, despite the essential role of ADH in this process (Rahman et al., 2001).

The induction of ADH and LDH activities in hypoxic roots of barley (Good and Crosby, 1989a) and maize (Christopher and Good, 1996) and of ADH in anoxic roots of soybean (Russell et al., 1990; Newman and VanToai, 1991) occurs by de novo synthesis. The increase in ADH1 (Gerlach et al., 1982) and LDH protein (Christopher and Good, 1996) was shown to correlate with increased transcript levels. A clearer picture of how these ANPs 
are induced at the transcriptional level is now emerging. Induction of ADH in maize and Arabidopsis involves a transcription factor that binds to an anaerobic response element (ARE) localized in the promoter and its production is probably important in the early response to $\mathrm{O}_{2}$ deficiency (Hoeren et al. 1998; Dennis et al., 2000). The ARE appears to be characteristic of genes induced by $\mathrm{O}_{2}$ deficiency which raises the interesting possibility that the identified transcription factor may be involved in the modulation of all ANPs (Dennis et al. 2000).

Transaminases also stand out among the enzymes of anaerobic metabolism, since they are ultimately responsible for the increase in content and interconversion of amino acids in anaerobic tissues, especially Ala and Gaba (Reggiani et al., 1988). In view of its role in catalyzing the final step of the main pathway of Ala biosynthesis, the enzyme AlaAT has received most attention among the transaminases. Work with roots of maize, wheat, barley and rye has shown an increase in activity of this enzyme under $\mathrm{O}_{2}$-deficiency, though not in leaves when the roots were under anaerobiosis (Good and Crosby, 1989b). In contrast to the ANPs, hypoxia but not anoxia led to the induction of AlaAT (Muench et al., 1998). The activity of AlaAT in hypoxic roots of barley increased approximately 4 times after 5 days of induction and was attributed to a single band of activity in analyses by PAGE. Nevertheless, working with the same cultivar of barley under the same conditions, Good and Muench (1992) detected two peaks of activity of AlaAT, during column chromatography by gel filtration, but only one of these peaks, which produced 4 isoenzymes by PAGE, was induced under $\mathrm{O}_{2}$ deficiency. The significance of this induction is not clear, since the accumulation of Ala precedes the bulk increase in activity of AlaAT in roots of barley (Good and Muench, 1993) and soybean (Sousa, 2001). Possibly, increased flow through AlaAT in the direction of Ala results initially from a rapid increase in pyruvate (Reggiani et al., 1988; Good and Muench, 1993) and fall in oxoglutarate (Reggiani et al., 1988), since substrate/product levels would affect transamination reactions in view of their high reversibility (Lea and Ireland, 1999).

\section{CONCLUSIONS}

The main products formed in plants under $\mathrm{O}_{2}$ deficiency are ethanol, lactate and Ala, all originating from pyruvate. The formation of ethanol and lactate enable the regeneration of reduced coenzymes and the generation of ATP, though the role of Ala is less clear. In general, although ethanol is not considered toxic, its diffusion out of cells represents a loss of carbon while lactate is correlated with acidification of the cytoplasm. Ala, on the other hand, may help in the regulation of intracellular $\mathrm{pH}$ without causing phytotoxicity.

The accumulation of Ala observed in plants under $\mathrm{O}_{2}$ deficiency in the roots occurs independently of the source of $\mathrm{N}$ and much before the bulk increase of AlaAT.

Although the reductive assimilation of $\mathrm{NO}_{3}^{-}$is cited as one of the metabolic events responsible for the attenuation of hypoxic stress, apparently through a reduction in cytoplasmic acidity, the role of $\mathrm{NO}_{3}^{-}$is still controversial.

Acknowledgements: The authors wish to thank the Conselho Nacional de Desenvolvimento Científico e Tecnológico (CNPq) and the Fundação de Amparo à Pesquisa do Estado de São Paulo (FAPESP) for research grants.

\section{REFERENCES}

Albrecht G, Biemelt S (1998) A comparative study on carbohydrate reserves and ethanolic fermentation in the roots of two wetland and non-wetland species after commencement of hypoxia. Physiol. Plant. 104:81-86.

Albrecht G, Biemelt S, Baumgartner S (1997) Accumulation of fructans following oxygen deficiency stress in related plant species with different flooding tolerances. New Phytol. 136:137-144.

Albrecht G, Kammerer S, Praznic W, Wiedenroth EM (1993) Frutan content of wheat seedlings (Triticum aestivum L.) under hypoxia and following re-aeration. New Phytol. 123:471-476.

Andreev VY, Generozova IP, Vartapetian BB (1991) Energy status and mitochondrial ultrastructure of excised pea root at anoxia and postanoxia. Plant Physiol. Biochem. 29:171-176.

Atwell BJ, Thomson CJ, Greenway H, Ward G, Waters I (1985) A study of the impaired growth of roots of Zea mays seedlings at low oxygen concentrations. Plant Cell Environ. 8:179-188.

Aurisano N, Bertani A, Reggiani R (1995) Involvement of calcium and calmodulin in protein and amino acid metabolism in rice roots under anoxia. Plant Cell Physiol. $36: 1525-1529$. 
Bacanamwo M, Purcell, LC (1999a) Soybean dry matter and $\mathrm{N}$ accumulation responses to flooding stress, $\mathrm{N}$ sources and hypoxia. J. Exp. Bot. 50:689-696.

Bacanamwo M, Purcell LC (1999b) Soybean root morphological and anatomical traits associated with acclimation to flooding. Crop Sci. 39:143-149.

Barrett-Lennard EG, Leighton PD, Buwalda F, Gibbs J, Armstrong W, Thomson CJ, Greenway H (1988) Effects of growing wheat in hypoxic nutrient solutions and of subsequent transfer to aerated solutions. I. Growth and carbohydrate status of shoots and roots. Aust. J. Plant Physiol. 15:585-598.

Barta AL (1987) Supply and partitioning of assimilates to roots of Medicago sativa L. and Lotus corniculatus L. under anoxia. Plant Cell Environ. 10:151-156.

Barta AL (1988) Response of field grown alfalfa to root waterlogging and shoot removal. II. Nitrogen and fermentation metabolism. Agron. J. 80:893-896.

Bailey-Serres J, Freeling M (1990) Hypoxic stress-induced changes in ribosomes of maize seedling roots. Plant Physiol. 94:1237-1243.

Bertani A, Brambilla I, Menegus F (1980) Effect of anaerobiosis on rice seedlings growth, metabolic rate, and fate of fermentation products. J. Exp. Bot. 31:325-331.

Botrel A, Magné C, Kaiser WM (1996) Nitrate reduction, nitrite reduction and assimilation in barley roots in response to anoxia. Plant Physiol. Biochem. 34:645-652.

Bouny JM, Saglio PH (1996) Glycolytic flux and hexokinase activities in anoxic maize root tips acclimated by hypoxic pretreatment. Plant Physiol. 111:187-194.

Chang WWP, Huang L, Shen M, Webster C, Burlingame AL, Roberts JKM (2000) Patterns of protein synthesis and tolerance of anoxia in root tips of maize seedlings acclimated to a low-oxygen environment, and identification of proteins by mass spectrometry. Plant Physiol. 122:295-318.

Christopher ME, Good AG (1996) Characterization of hypoxically inducible lactate dehydrogenase in maize. Plant Physiol. 112:1015-1022.

Crawford LA, Bown AW, Breitkreuz KE, Guinel FC (1994) The synthesis of $\gamma$-aminobutyric acid in response to treatments reducing cytosolic pH. Plant Physiol. 104:865-871.

Davies DD, Grego S, Kenworthy P (1974) The control of the production of lactate and ethanol by higher plants. Planta 118:297-310.

De la Haba P, Aguera E, Beuítez L, Maldonado JM (2001) Modulation of nitrate reductase activity in cucumber (Cucumis sativus) roots. Plant Sci. 161:231-237.
Dennis ES, Dolferus R, Ellis M, Rahman M, Wu Y, Hoeren FU, Grover A, Ismond KP, Good AG, Peacock WJ (2000) Molecular strategies for improving waterlogging tolerance in plants. J. Exp. Bot. 51:89-97.

Drew MC (1990) Sensing soil oxygen. Plant Cell Environ. 13:681-693.

Drew MC (1997) Oxygen deficiency and root metabolism: injury and acclimation under hypoxia and anoxia. Annu. Rev. Plant. Physiol. Plant Mol. Biol. 48:223-250.

Edwards S, Nguyen B-T, Roberts JKM (1998) Contribution of malic enzyme, pyruvate kinase, phosphoenolpyruvate carboxylase, and the Krebs cycle to respiration and biosynthesis and to intracellular $\mathrm{pH}$ regulation during hypoxia in maize root tips observed by nuclear magnetic resonance imaging and gas chromatography-mass spectrometry. Plant Physiol. 116:1073-1081.

Fan TW-M, Higashi RM, Frenkiel TA, Lane AN (1997) Anaerobic nitrate and ammonium in flood-tolerant rice coleoptiles. J. Exp. Bot. 48:1655-1666.

Fan TW-M, Higashi RM, Lane AN (1988) An in vivo ${ }^{1} \mathrm{H}$ and ${ }^{31} \mathrm{P}$ NMR investigation of the effect of nitrate on hypoxic metabolism in maize roots. Arch. Biochem. Biophys. 266:592-606.

Fox TC, Kennedy RA, Rumpho ME (1994) Energetics of plant growth under anoxia: metabolic adaptations of Oryza sativa and Echinochloa phyllopogon. Ann. Bot. 74:445-455.

Garcia-Novo F, Crawford, RMM (1973) Soil aeration, nitrate reduction and flooding tolerance in higher plants. New Phytol. 72:1031-1039.

Gerlach WL, Pryor AJ, Dennis ES, Ferl RJ, Sachs MM, Peacock WJ (1982) cDNA cloning and induction of the alcohol dehydrogenase gene (Adh1) of maize. Proc. Nat. Acad. Sci. (USA): 79:2981-2985.

Germain V, Ricard B, Raymond P, Saglio PH (1997) The role of sugars, hexokinase, and sucrose synthase in the determination of hypoxically induced tolerance to anoxia in tomato roots. Plant Physiol. 114:167-175.

Glaab J, Kaiser WM (1993) Rapid modulation of nitrate reductase in pea roots. Planta 191:173-179.

Good AG, Crosby W (1989a) Induction of alcohol dehydrogenase and lactate dehydrogenase in hypoxically induced barley. Plant Physiol. 90:860-866.

Good AG, Crosby W (1989b) Anaerobic induction of alanine aminotransferase in barley root tissue. Plant Physiol. 90:1305-1309.

Good AG, Muench DG (1992) Purification and characterization of an aerobically induced alanine aminotransferase from barley roots. Plant Physiol. 99:1520-1525. 
Good AG, Muench DG (1993) Long-term anaerobic metabolism in root tissue. Plant Physiol. 101:1163-1168.

Gout E, Boisson AM, Aubert S, Douce R, Bligny R (2001) Origin of the cytoplasmic $\mathrm{pH}$ changes during anaerobic stress in higher plant cells. Carbon-13 and phosphorous31 nuclear magnetic resonance studies. Plant Physiol. 125:912-925.

Guglielminetti L, Perata P, Alpi A (1995) Effect of anoxia on carbohydrate metabolism in rice seedlings. Plant Physiol. 108:735-741.

Hoeren FU, Dolferus R, Wu Y, Peacock WJ, Dennis ES (1998) Evidence for a role for AtMYB2 in the induction of the Arabidopsis alcohol dehydrogenase gene $(A D H 1)$ by low oxygen. Genetics 149:479-490.

Huang B, Johnson JW (1995) Root respiration and carbohydrate status of two wheat genotypes in response to hypoxia. Ann. Bot. 75:427-432.

Huang B, Johnson JW, NeSmith S, Bridge DC (1994a) Root and shoot growth of wheat genotypes in response to hypoxia and subsequent resumption of aeration. Crop Sci. 34:1538-1544.

Huang B, Johnson JW, NeSmith S, Bridge DC (1994b) Growth, physiological and anatomical responses of two wheat genotypes to waterlogging and nutrient supply. J. Exp. Bot. 45:193-202.

Jackson MB, Herman B, Goodenough A (1982) An examination of the importance of ethanol in causing injury to flooded plants. Plant Cell Environ. 5:163-172.

Johnson JR, Cobb BG, Drew MC (1994) Hypoxic induction of anoxia tolerance in roots of adh1 null Zea mays $\mathrm{L}$. Plant Physiol. 105:61-67.

Joly CA (1994) Flooding tolerance: a reinterpretation of Crawford's metabolic theory. Proc. Royal Soc. Edinburgh 102B:343-354.

Kaiser WM, Huber SC (2001) Post-translational regulation of nitrate reductase: mechanism, physiological relevance and environmental triggers. J. Exp. Bot. 52:1981-1989.

Kaiser WM, Weiner H, Kandlbinder A, Tsai CB, Rockel P, Sonoda M, Planchet E (2002) Modulation of nitrate reductase: some new insights, an unusual case and a potentially important side reaction. J. Exp. Bot. 53:875-882.

Kato-Noguchi H (2000) Evaluation of the importance of lactate for the activation of ethanolic fermentation in the lettuce in anoxia. Physiol. Plant. 109:28-33.

Kemp K, Small JGC (1993) Nitrate and nitrate reductase in Erythrina caffra seeds: enhancement of induction by anoxia and possible role in germination. Planta 189:298300 .
Kennedy RA, Rumpho ME, Fox TC (1992) Anaerobic metabolism in plants. Plant Physiol. 100:1-6.

Kinnersley AM, Turano FJ (2000) Gamma aminobutyric acid (GABA) and plant responses to stress. Crit. Rev. Plant Sci. 19:479-509.

Lea PJ, Ireland RJ (1999) Nitrogen metabolism in higher plants. In: Singh BK (ed.), Plant Amino Acids. Biochemistry and Biotechnology, pp.1-47. Marcel Dekker, New York, United States

Lee RB (1978) Inorganic nitrogen metabolism in barley roots under poorly aerated conditions. J. Exp. Bot. 29:693-708.

Lee RB (1979) The release of nitrite from barley roots in response to metabolic inhibitors, uncoupling agents and anoxia. J. Exp. Bot. 30:119-133.

Liao CT, Lin CH (1994) Effect of flooding stress on photosynthetic activities of Momordica charantia. Plant Physiol. Biochem. 32:479-485.

Limpinuntana V, Greenway H (1979) Sugar accumulation in barley and rice grown in solutions with low concentrations of oxygen. Ann. Bot. 43:373-381.

Lin CY, Key JL (1967) Dissociation and reassembly of polyribosomes in relation to protein synthesis in the soybean root. J. Mol. Biol. 26:237-247.

Magalhães JR, Silva FLIM, Salgado I, Ferrarese-Filho O, Rockel P, Kaiser WM (2002) Nitric oxide and nitrate reductase in higher plants. Physiol. Mol. Biol. Plants 8:1117.

Malavolta E (1954) Studies on the nitrogenous nutrition of rice. Plant Physiol. 29:98-99.

Mattana M, Brambilla I, Bertani A, Reggiani R (1996) Expression of nitrogen assimilating enzymes in germinating rice under anoxia. Plant Physiol. Biochem. 34:653-657.

Menegus F, Cattaruzza L, Chersi A, Fronza G (1989) Differences in the anaerobic lactate-succinate production and in the changes of cell sap $\mathrm{pH}$ for plants with high and low resistance to anoxia. Plant Physiol. 90:29-32.

Menegus F, Cattaruzza L, Chersi A, Selva A (1988) Production and organ distribution of succinate in rice seedlings during anoxia. Physiol. Plant. 74:444-449.

Menegus F, Cattaruzza L, Mattana M, Beffagna N, Ragg E (1991) Response to anoxia in rice and wheat seedlings. Changes in $\mathrm{pH}$ of intracellular compartments, glucose6-phosphate level, and metabolic rate. Plant Physiol. 95:760-767.

Morard P, Silvestre J (1996) Plant injury due to oxygen deficiency in the root environment of soilless culture: a review. Plant and Soil 184:243-254. 
Muench DG, Christopher ME, Good AG (1998) Cloning and expression of a hypoxic and nitrogen inducible maize alanine aminotransferase gene. Physiol. Plant. 103:503512.

Naidoo G, Naidoo S (1992) Waterlogging responses of Sporolobus virginicus (L.) Kunth. Oecologia 90:445-450.

Newman KD, VanToai TT (1991) Developmental regulation and organ specific expression of soybean alcohol dehydrogenase. Crop Sci. 31:1253-1257.

Perata P, Alpi A (1993) Plant responses to anaerobiosis. Plant Sci. 93:1-17.

Porterfield DM, Crispi ML, Musgrave ME (1997) Changes in soluble sugar, starch, and alcohol dehydrogenase in Arabidopsis thaliana exposed to $\mathrm{N}_{2}$ diluted atmospheres. Plant Cell Physiol. 38:1354-1358.

Prioul JL, Guyot C (1985) Role of oxygen transport and nitrate metabolism in the adaptation of wheat plants to root anaerobiosis. Physiol. Veg. 23:175-185

Puiatti M, Sodek L (1999) Waterlogging affects nitrogen transport in the xylem of soybean. Plant Physiol. Bioch. 37:767-773.

Rahman M, Grover A, Peacock WJ, Dennis ES, Ellis MH (2001) Effects of manipulation of pyruvate decarboxylase and alcohol dehydrogenase levels on the submergence tolerance of rice. Aust. J. Plant Physiol. 28:12311241.

Reggiani R (1999) Amino acid metabolism under oxygen deficiency. Phytochemistry 2:171-174.

Reggiani R, Brambilla I, Bertani A (1985) Effect of exogenous nitrate on anaerobic metabolism in excised rice roots. II. Fermentation activity and adenylic energy charge. J. Exp. Bot. 36:1698-1704.

Reggiani R, Cantú CA, Brambilla I, Bertani A (1988) Accumulation and interconversion of amino acids in rice roots under anoxia. Plant Cell Physiol. 29:982-987.

Reggiani R, Mattana M, Aurisano N, Bertani A (1993a) Utilization of stored nitrate during the anaerobic germination of rice seeds. Plant Cell Physiol. 34:379-383.

Reggiani R, Mattana M, Aurisano N, Bertani A (1993b) The rice coleoptile: an example of anaerobic nitrate assimilation. Physiol. Plant. 89:640-643.

Reggiani R, Nebuloni M, Mattana M, Brambilla I (2000) Anaerobic accumulation of amino acids in rice roots: role of the glutamine synthetase/glutamate synthase cycle. Amino Acids 18:207-217.

Ricard B, Couée I, Raymond P, Saglio PH, Saint-Ges V, Pradet A (1994) Plant metabolism under hypoxia and anoxia. Plant Physiol. Biochem. 32:1-10.
Rivoal J, Hanson AD (1994) Metabolic control of anaerobic glycolysis. Overexpression of lactate dehydrogenase in transgenic tomato roots supports the Davies-Roberts hypothesis and points to a critical role for lactate secretion. Plant Physiol. 106:1179-1185.

Roberts JKM, Andrade F, Anderson IC (1985) Further evidence that cytoplasmic acidosis is a determinant of flooding intolerance in plants. Plant Physiol. 77:492-494.

Roberts JKM, Chang K, Webster C, Callis J, Walbot V (1989) Dependence of ethanolic fermentation, cytoplasmic $\mathrm{pH}$ regulation, and viability on the activity of alcohol dehydrogenase in hypoxic maize root tips. Plant Physiol. 89:1275-1278.

Roberts JKM, Hooks MA, Miaullis AP, Edwards S, Webster C (1992) Contribution of malate and amino acid metabolism to cytoplasmic $\mathrm{pH}$ regulation in hypoxic maize root tips studied using nuclear magnetic resonance spectroscopy. Plant Physiol. 98:480-487.

Rockel P, Strube F, Rockel A, Wildt J, Kaiser WM (2002) Regulation of nitric oxide (NO) production by plant nitrate reductase in vivo and in vitro. J. Exp. Bot. 53:103110 .

Russell DA, Wong DM-L, Sachs MM (1990) The anaerobic response of soybean. Plant Physiol. 92:401-407.

Sachs MM, Freeling M, Okimoto R (1980) The anaerobic proteins of maize. Cell 20:761-767.

Sachs MM, Subbaiah CC, Saab IN (1996) Anaerobic gene expression and flooding tolerance in maize. J. Exp. Bot. 47:1-15.

Saint-Ges V, Roby C, Bligny R, Pradet A, Douce R (1991) Kinetic studies of the variations of cytoplasmic $\mathrm{pH}$, nucleotide triphosphates ( $\left.{ }^{31} \mathrm{P}-\mathrm{NMR}\right)$ and lactate during normoxic and anoxic transitions in maize roots tips. Eur. J. Biochem. 200:477-482.

Salsac L, Sylvain C, Morot-Gaudry J-F, Lesaint C, Jolivet E (1987) Nitrate and ammonium in plants. Plant Physiol. Biochem. 25:805-812.

Schlüter U, Albrecht G, Wiedenroth E-M (1996) Content of water soluble carbohydrates under oxygen deprivation in plants with different flooding tolerance. Folia Geobot. Phytotax. 31:57-64.

Serraj R, Barry JS, Sinclair TR (1998) Accumulation of $\gamma$ aminobutyric acid in nodulated soybean in response to drought stress. Physiol. Plant. 102:79-86.

Shelp BJ, Bown AW, McLean MD (1999) Metabolism and functions of gamma-aminobutyric acid. Trends Plant Sci. 4:446-452. 
Smirnoff N, Stewart GR (1985) Nitrate assimilation and translocation by higher plants: comparative physiology and ecological consequences. Physiol. Plant. 64:133-140.

Smith A, ap Rees T (1979) Pathways of carbohydrate fermentation in the roots of marsh plants. Planta 146:327334.

Snedden WA, Chung I, Pauls RH, Bown AW (1992) Proton/ L-glutamate symport and the regulation of intracellular pH isolated mesophyll cells. Plant Physiol. 99:665-671.

Sousa CAF (2001) Metabolismo de nitrogênio em plantas de soja [Glycine max (L.) Merr. cv IAC-17] submetidas à deficiência de $\mathrm{O}_{2}$ no sistema radicular. Campinas, Universidade Estadual de Campinas. Tese de Doutorado.

Sousa CAF, Sodek L (2002) Metabolic changes in soybean plants in response to waterlogging in the presence of nitrate. Physiol. Mol. Biol. Plants 8:97-104.

Streeter JG, Thompson JF (1972a) Anaerobic accumulation of $\gamma$-aminobutyric acid and alanine in radish leaves (Raphanus sativus L.). Plant Physiol. 49:572-578.

Streeter JG, Thompson JF (1972b) In vivo and in vitro studies on $\gamma$-aminobutyric acid metabolism with the radish plant (Raphanus sativus L.). Plant Physiol. 49:579-584.

Thompson CJ, Greenway H (1991) Metabolic evidence for stelar anoxia in maize roots exposed to low $\mathrm{O}_{2}$ concentrations. Plant Physiol. 96:1294-1301.

Trought MCT, Drew MC (1981) Alleviation of injury to young wheat plants in anaerobic solution cultures in relation to the supply of nitrate and other inorganic nutrients. J. Exp. Bot. 32: 509-522.

Vanlerberghe GC, Feil R, Turpin DH (1990) Anaerobic metabolism in the N-limited green alga Selenastrum minutum. I. Regulation of carbon metabolism and succi- nate as a fermentation product. Plant Physiol. 94:11161123.

Vanlerberghe GC, Horsey AK, Weger HG, Turpin DH (1989) Anaerobic carbon metabolism by the tricarboxylic acid cycle. Evidence for partial oxidative and reductive pathways during dark ammonium assimilation. Plant Physiol. 91:1551-1557.

Vanlerberghe GC, Turpin DH (1990) Anaerobic metabolism in the N-limited green alga Selenastrum minutum. II. Assimilation of ammonium by anaerobic cells. Plant Physiol. 94:1124-1130.

Vanlerberghe GC, Joy KW, Turpin DH (1991) Anaerobic metabolism in the N-limited green alga Selenastrum minutum. III. Alanine is the product of anaerobic ammonium assimilation. Plant Physiol. 95:655-658.

VanToai TT, Bolles CS (1991) Postanoxic injury in soybean (Glycine max) seedlings. Plant Physiol. 97:588-592.

Wallace W, Secor J, Schrader E (1984) Rapid accumulation of $\gamma$-aminobutyric acid and alanine in soybean leaves in response to an abrupt transfer to lower temperature, darkness, or mechanical manipulation. Plant Physiol. 75:170175.

Waters I, Kuiper PJC, Watkin E, Greenway H (1991a) Effects of anoxia on wheat seedlings. I. Interaction between anoxia and other environmental factors. J. Exp. Bot. 42:1427-1435.

Waters I, Morrell S, Greenway H, Colmer TD (1991b) Effects of anoxia on wheat seedlings. II. Influence of $\mathrm{O}_{2}$ supply prior to anoxia on tolerance to anoxia, alcoholic fermentation, and sugar levels. J. Exp. Bot. 42:1437-1447.

Xia J-H, Saglio PH (1992) Lactic acid efflux as a mechanism of hypoxic acclimation of maize root tips to anoxia. Plant Physiol. 100:40-46. 